\title{
Extracción de cálculo coledociano de gran tamaño con esfinterotomía biliar seguida de dilatación de la papila con balón hidrostático
}

\author{
J. García-Cano, A. Pérez Sola, C. J. Gómez Ruiz, M. Viñuelas Chicano, C. Jimeno Ayllón y N. Sánchez \\ Manjavacas
}

Sección de Aparato Digestivo. Hospital Virgen de la Luz. Cuenca

Una paciente de 83 años ingresó por dolor de tipo cólico en hipocondrio derecho y alteración colestásica de las enzimas hepáticas. En la ecografía abdominal transcutánea se observó dilatación importante de la vía biliar extrahepática,

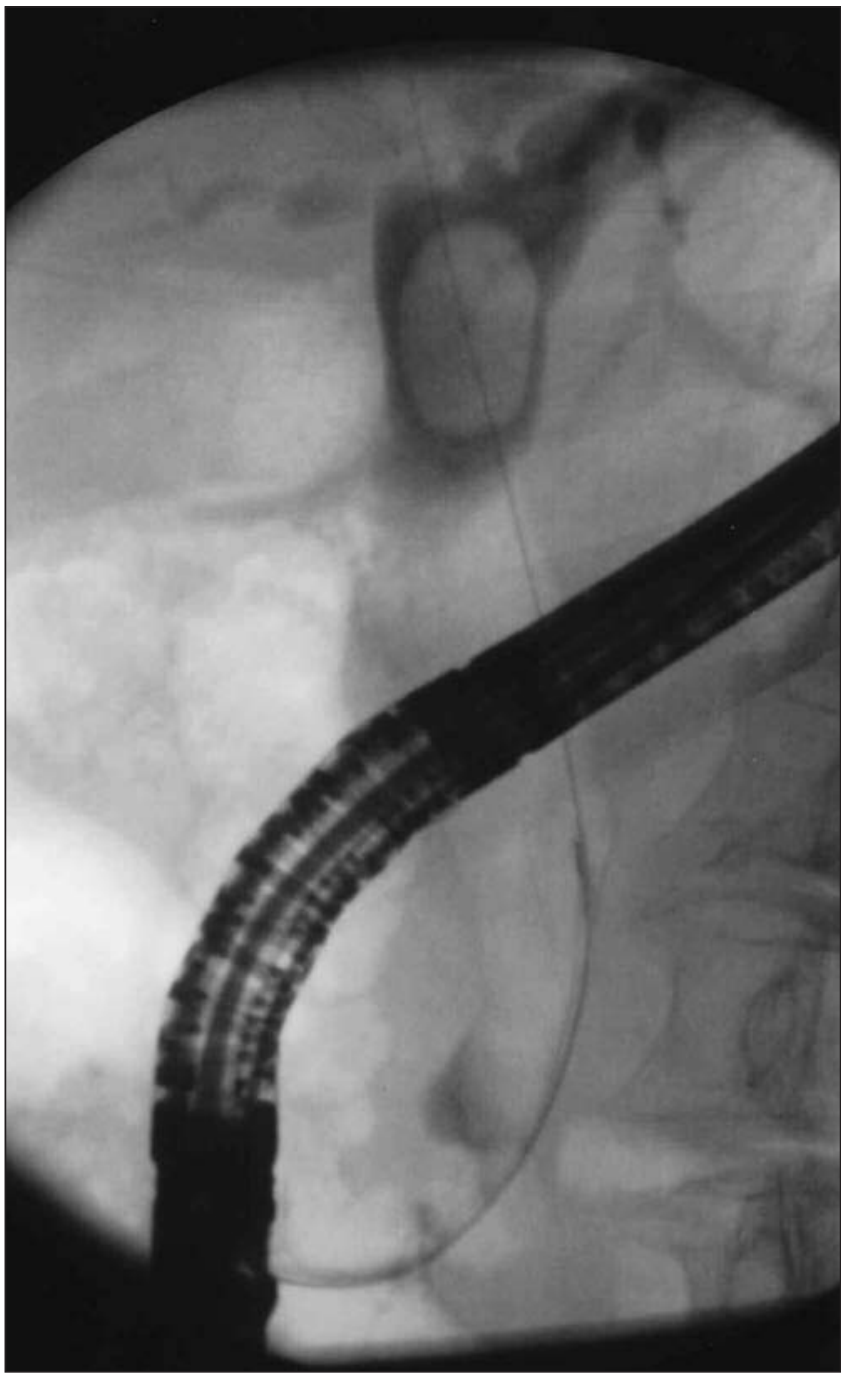

Fig. 1. CPRE en la que se observa una gran coledocolitiasis en la parte superior de la vía biliar extrahepática. visualizándose también una litiasis coledociana distal. Se realizó una colangiopancreatografía retrógrada endoscópica (CPRE). La papila estaba situada en el borde derecho de un divertículo duodenal. En la colangiografía se observó una coledocolitiasis de forma ovoidea de unos $19 \mathrm{~mm}$ de diámetro máximo (Fig. 1). Se realizó una esfinterotomía biliar endoscópica. Por la posición yuxtadiverticular de la papila de Vater, el tamaño de la esfinterotomía no pudo ser mayor de aproximadamente $5 \mathrm{~mm}$. Con esta abertura papilar no parecía posible extraer la coledocolitiasis. Se procedió entonces a dilatar la esfinterotomía con un balón hidróstático de $15 \mathrm{~mm}$ de diámetro (Figs. 2 y 3 ). A continuación se pasó un balón extractor de cálculos y pudo extraerse la coledocolitiasis (Fig. 4). Aunque el tamaño de esta era mayor que el de la dilatación de la papila, la coledocolitiasis pudo deslizarse con facilidad por el orificio papilar dilatado.

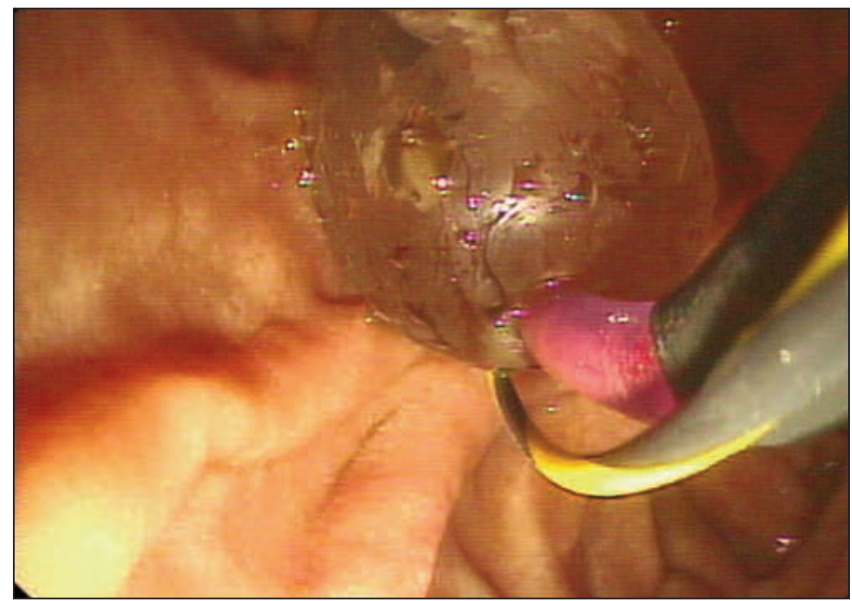

Fig. 2. Imagen endoscópica de la dilatación de la esfinterotomía biliar con un balón de $15 \mathrm{~mm}$ de diámetro. 


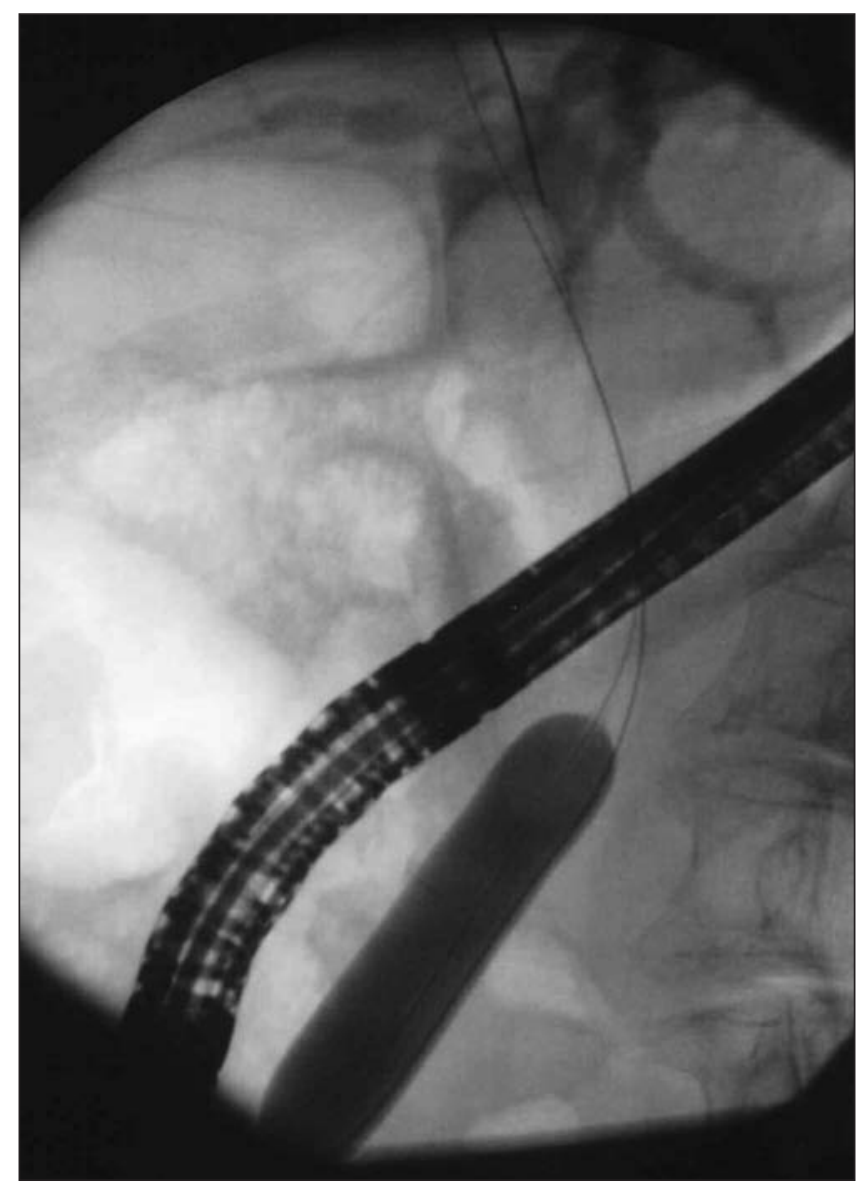

Fig. 3. Imagen radiológica de la dilatación de la esfinterotomía biliar. El balón se ha hinchado con una mezcla de agua y contraste radiológico para que sea radioopaco.

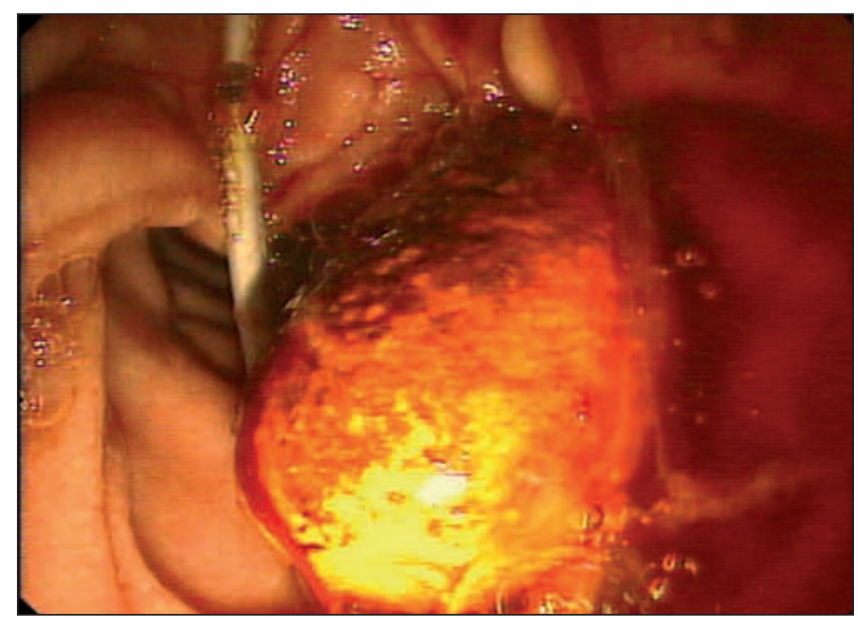

Fig. 4. Coledocolitiasis extraída en el duodeno.

La extracción endoscópica (por CPRE) de coledocolitiasis se realiza desde 1973. Cuando sólo se utilizaban balones extractores y cestas de Dormia, la tasa de extracción completa en el primer intento endoscópico oscilaba en torno al $70 \%$ (1). La dilatación de la papila de Vater tras la esfinterotomía biliar con balones hidrostáticos de diámetro grande $(12-20 \mathrm{~mm})$ es un procedimiento sencillo, recientemente instaurado (2), que consigue unas tasas de extracción total cercanas al $100 \%$. Además, al realizar una pequeña esfinterotomía, la compresión que ocasiona el balón dilatado se dirige más hacia el esfínter biliar que hacia el pancreático. Este hecho hace que se produzcan pancreatitis con menos frecuencia y parece ser distinto a cuando se dilata la papila intacta sin haberla seccionado previamente (3).

\section{BIBLIOGRAFÍA}

1. García-Cano Lizcano J, González Martín JA, Pérez Sola A, Morillas Ariño MJ. Tasa de extracción completa de coledocolitiasis al primer intento endoscópico. Rev Esp Enferm Dig 2002; 94: 340-5.

2. Espinel J, Pinedo E, Olcoz JL. Balón hidrostático de gran diámetro en coledocolitiasis. Rev Esp Enferm Dig 2007; 99: 33-8.

3. García-Cano J. Fatal pancreatitis after endoscopic balloon dilation for extraction of common bile duct stones in an 80-year-old woman. Endoscopy 2006; 38: 431 . 